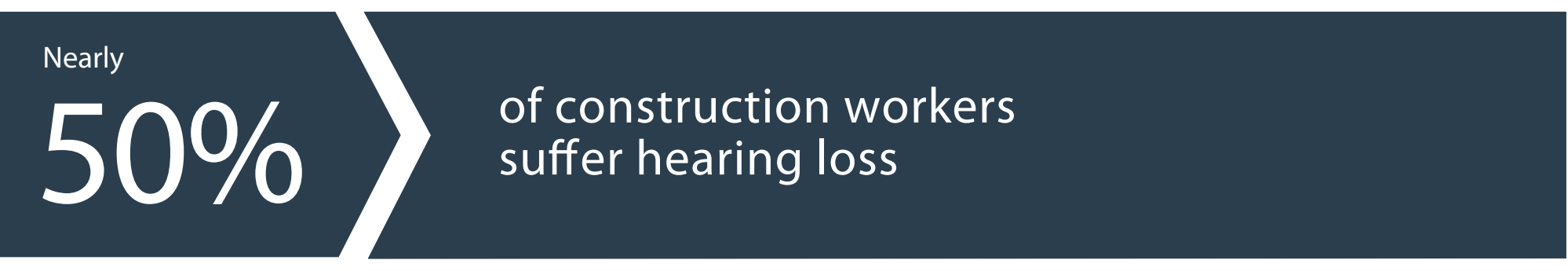

\title{
HEARING LOSS IS PREVENTABLE and you can do something about it...
}

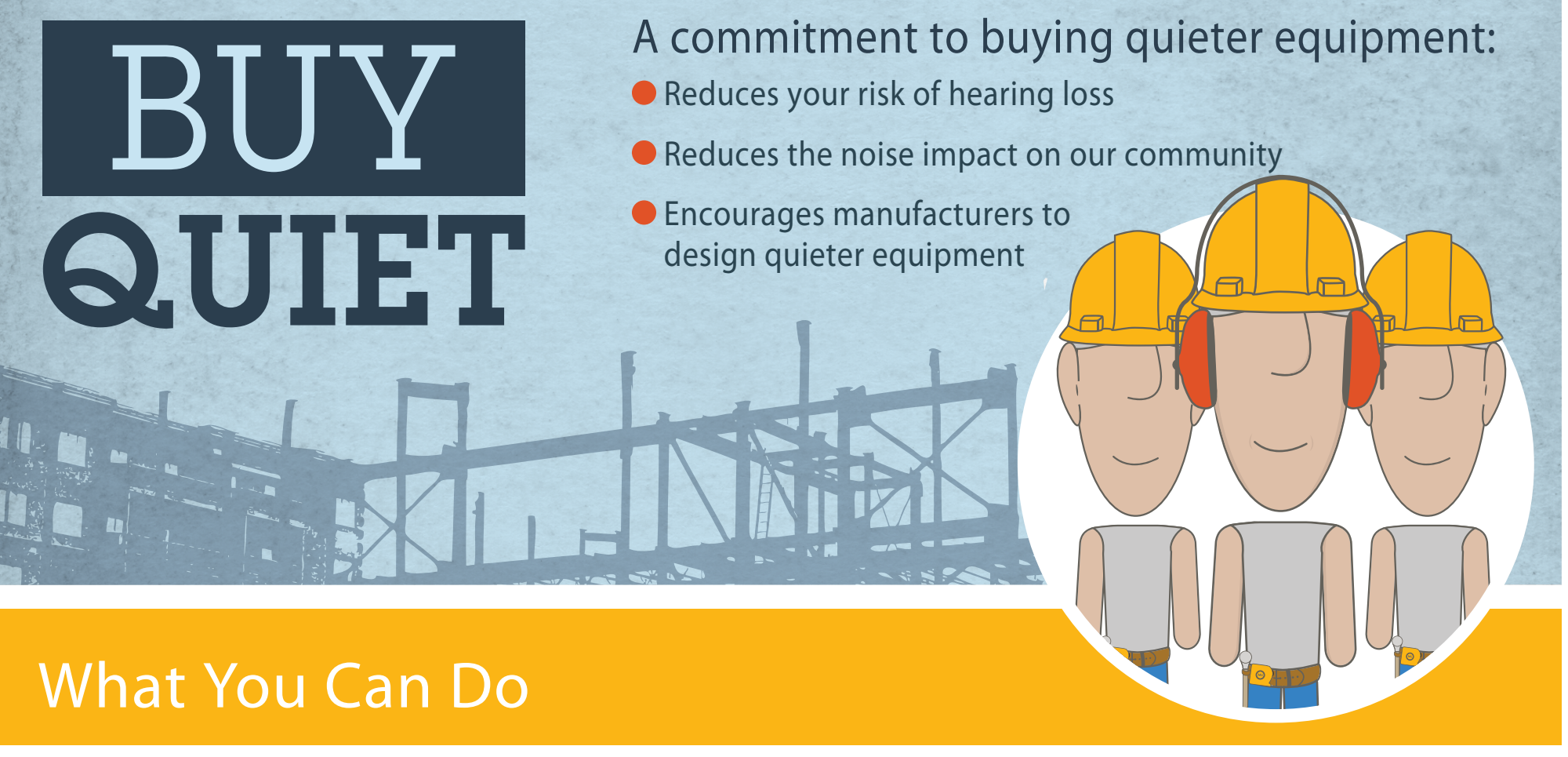

Even with quieter equipment, it is important that you continue to protect your hearing:

- Wear protective earmuffs or earplugs

- Move sources of loud noise such as compressors away from the work zone

- Take breaks when operating loud equipment

- Get your hearing checked regularly

DEPARTMENT OF HEALTH AND HUMAN SERVICES

Centers for Disease Control and Prevention

National Institute for Occupational Safety and Health www.cdc.gov/niosh/topics/buyquiet

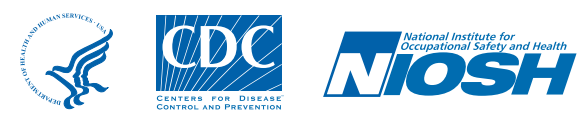

DHHS (NIOSH) Pub. No. 2014-128

SAFER • HEALTHIER • PEOPLE ${ }^{\text {TM }}$ 